\title{
LA FRACTURA EN LA SOCIEDAD POLÍTICA CATALANA EN VÍSPERAS DEL COMPROMISO DE CASPE
}

\author{
J. ÁNGEL SESMA MUÑOZ \\ Universidad de Zaragoza
}

\begin{abstract}
SUMARIO
I. El problema del cuarto brazo.- II. Los dos bandos de la nobleza catalana.- III. Los enfrentamientos entre los dos bandos nobles.- IV. Epílogo.Apéndice I.- Apéndice II.
\end{abstract}

La muerte de Martín I y el inicio, por tanto, del interregno que concluirá con el Compromiso de Caspe, pone fin, en Cataluña, a una larga y complicada reunión de Cortes prolongada durante los cinco años anteriores y en cuyo transcurso se habían manifestado las enormes diferencias existentes en el seno de las elites de poder del principado.

A estas Cortes, sin duda unas de las más conflictivas y accidentadas de todas las celebradas en Cataluña, fueron convocados los brazos por el rey desde Barcelona el 27 de julio de $1405^{1}$ para el 30 de septiembre en Perpiñán, si bien no pudieron abrirse hasta el mes de enero siguiente²;

\footnotetext{
'Se enviaron citaciones a un total de 42 miembros del estamento eclesiástico (arzobispo, obispos, capítulos catedralicios, castellán de Amposta y 25 monasterios). 9 condes, vizcondes y barones, 35 nobles, 61 caballeros. 26 donceles y 19 ciudades y villas reales. En total 192 cartas.

'El 26 de enero de 1406, el rey, desde su solio, teniendo a la izquierda a los barones, nobles, caballeros y generosos, a la derecha a los prelados y religiosos y frente a él a los procuradores de las universidades, inició su proposición, que a juzgar por el lema elegido ("gloriosa dicta sunt de te") y su anuncio inmediato de "parlar de la gloria del principat de Cathalunya", abría una reunión que Martín esperaba que fuera difícil y complicada. Termina reconociemdo que hacía tiempo que no se habían celebrado Cortes ni se habían acometido las

"Anuario de Estudios Medicvales". 29 (1999)
} 
inmediatamente, tres días después de hacer su proposición, el monarca, entre fuertes protestas, las suspendió y las trasladó al monasterio de Sant Cugat a partir del 15 de marzo (en la práctica hasta finales de abril); aquí, en mayo, la presión le obligó a una nueva suspensión, prevista hasta el mes de agosto siguiente pero que se prolongó hasta junio de 1408 , tiempo empleado por el General, sin la presencia real, para discutir acaloradamente la configuración de la asamblea, cuestiones de procedimiento, la habilitación de los procuradores y síndicos y la formación de comisiones que trataran de alcanzar acuerdos. Con los ánimos muy exaltados y las posturas de los grupos muy radicalizadas, ese mismo mes de junio de 1408 se llevaron a Barcelona, al convento de los frailes menores, donde en un ambiente muy crispado, con prolongados períodos de negociaciones al margen de las propias Cortes, con muy escasos compromisos unánimes y fuertes rupturas de la convivencia, discurrieron hasta que se extinguieron el 31 de mayo de 1410 por el fallecimiento del monarca ${ }^{3}$.

Las actas de tan largo proceso ${ }^{4}$ mencionan muchos de los acontecimientos políticos de la Corona en ese tiempo; aspectos tan decisivos como el endeudamiento de la monarquía, la guerra de Cerdeña, la muerte del príncipe Martín que dejaba el trono sin heredero y los primeros movimientos de búsqueda de sucesión pasan por la asamblea, al parecer, sin discusión ni especial preocupación ${ }^{5}$. Sin embargo, el texto no alude en ninguna ocasión

necesidades del principado, por lo que se ofrecia para solucionar "torts y greuges" de tiempos de su padre, su hermano y él mismo y les ruega que "asi com la vostra liberalitat" se había manifestado con sus predecesores, la pongan en práctica ahora también.

${ }^{3} \mathrm{E}$ dia anterior, viernes 30 , como se venía haciendo desde meses atrás, al término de una sesión sin conclusiones, el regente de la cancillería, en nombre del rey, había prorrogado las Cortes para el sábado por la tarde: y será en esta reunión cuando se indique que ese día "circa horam undecimam ... dictus serenissimus dominus rex Martinus, qui hujusmodi Curiarum in presenti processu descriptarum convocaverat et celebrabat. eius spiritum reddidit Creattori ... et sic dicta Curia suum obtinuit finem".

¿Están publicadas en los tomos V y VI de las Cortes de los antiguos reinos de Aragón y de Valencia y principado de Cataluna. Cortes de Cataluña. Real Academia de la Historia, Madrid. 1901-1902. Todas las citas se remiten a esta edición.

5omo ejemplo, la muerte del infante Martín, que es conocida por las Cortes cuando el 5 de agosto de 1409, extra Curiam. por no estar convocada para ese día, el rey pide consejo a los brazos. La respuesta, en la sesión del día 7. se redacta en una cédula de dos párrafos. En el primero, reconociendo "la arduhidat de la materia proposada, gran pes. perills e dans dels negocis". que afecta a todas las tierras y reinos, le proponen la convocatoria inmediata de Cortes Generales de la Corona y alli "la dita Cort emsemps ab los altres donara son consell. sperant en la divinal gracia que sen seguira exalçament a la suya Reyal Corona e profit a sos regnes e terres". En el segundo párrafo, le suplican a Martín atienda a la "bona reparacio dels greuges dei dit Principat". 
a problemas que pudiera padecer la masa social catalana, ni propone mejoras en la convivencia de la población. La atención de los debates sostenidos en las Corts se centra en las cuestiones próximas que afectaban a los asistentes - la defensa de sus prorrogativas estamentales, las cuestiones de procedimiento, las condiciones impuestas a las peticiones del rey o la protesta ante las propuestas de cualquiera de los otros brazos-, mostrándonos, a través de su cuidada redacción, su meditado planteamiento teórico y su estudiada secuencia cronológica, el deterioro de la relación entre la monarquía y los brazos, la nula conexión entre estos y el cuerpo social y, sobre todo, el profundo desasosiego existente entre los grupos privilegiados, que debidamente actualizadas habían arrastrado las antiguas diferencias al seno del parlamento, ya convertido en foro de debate político no sólo de los brazos en representación del reino frente al rey, sino, lo que puede ser más importante en la concepción del parlamentarismo moderno, de los bandos o parcialidades (adherencias, las denominan ellos) surgidos en los estamentos tradicionales.

En la Corona de Aragón el tránsito del siglo XIV al XV constituye el momento decisivo en la formulación de las nuevas estructuras políticas; el reparto del poder entre los grupos dirigentes en cada uno de los territorios y en el conjunto las habían conducido en una dirección determinada y lo mismo ocurrirá con la solución dada en Caspe a la sucesión de Martín I; al final, la consecuencia será la larga fase de inestabilidad política y social que se prolongará toda la centuria hasta culminar en la sublevación de Cataluña en tiempos de Juan II. El desarrollo de estas Cortes de Perpiñán-Sant CugatBarcelona nos muestra con gran precisión la pésima situación interna de la sociedad política catalana, la falta de voluntad por impulsar cambios y un proyecto común y su incapacidad para interesarse por los serios problemas que afectaban al principado; como resultado, su inexorable pérdida de peso político en el conjunto de la Corona"

\footnotetext{
${ }^{6}$ Como simple muestra, podemos señalar que en mitad de las disputas de estas Cortes, en mayo de 1406, Martín informa que debido a ciertos asuntos en Valencia que reclaman su presencia, ha decidido acudir alli y dejar "tots altres affers" pendientes; las protestas de los brazos no le afectan, ni siquiera la del noble Berenguer de Olms, que comienza glosando el "Domine quo vadis", y reclama la atención real a los problemas catalanes que son graves y de enormes consecuencias: "tum propter discordias et odia que inter universalia brachia et status ipsius principatus sunt ... tum propter duram guerrarum civilium et militarium conmocionem que fere in omnibus artibus Catalonie inhumaniter pullulat et concrescit". El rey abandona las Cortes y tardará más de dos años, hasta el 27 de junio de 1408, en volver a ellas.
} 
Dejando para un trabajo más extenso el análisis comparativo de los grupos dirigentes de Aragón, Cataluña y Valencia a través de sus comportamientos en las reuniones parlamentarias de ese período ${ }^{7}$, voy a concentrar mi atención en los dos asuntos que consumen la casi totalidad de las enegías de los asistentes y provocan la mayoría de las actuaciones emprendidas en estas Cortes de 1405-1410. Por un lado, la propuesta de división del bloque militar con la creación de un cuarto brazo que englobe a los caballeros y donceles; por otro, la radical ruptura en dos bandos de la nobleza del principado, que impide cualquier acuerdo y provoca la inoperancia de la asamblea; en medio queda la falta de tensión política del rey y sus asesores, también incapaces de marcar ningún rumbo.

\section{EL PROBLEMA DEL CUARTO BRAZO}

Las Cortes de Aragón, posiblemente desde sus orígenes, se articulan en cuatro brazos: Iglesia, Ricoshombres, Caballeros y Universidades, como consecuencia de la estructura adquirida por la clase militar y la ordenación como grupo independiente de los caballeros durante los acontecimientos de la primera Unión. Su poder militar y su extensión social les dieron fuerza política, entrando a formar parte como estamento de pleno derecho en las Cortes al constituirse éstas en órganos de participación de los poderes fácticos junto al rey.

En Cataluña las peculiares condiciones de partida, con la existencia de potentes barones (condes y vizcondes) que aglutinaban la capacidad guerrera y disponían de jurisdicción en grandes áreas, impidieron un movimiento similar hasta mediados del siglo XIV, cuando la reacción de los magnates ante la crisis y la política de Pedro IV de potenciar la monarquía hicieron surgir el movimiento reivindicador de la caballería, oscuramente aprovechado por los barones, no sólo en el ámbito de las armas sino también

\footnotetext{
${ }^{7}$ Contrasta con lo ocurrido en las Cortes aragonesas celebradas en el verano de 1404 en Maella [ed. por M. Luisa LEDESMA RUBIO, "EEMCA", IX (1973), pp. 527-639], reunidas por Martín I a petición de los diputados de Aragón y en las que en cuatro sesiones se procedió a reparar la fiscalidad sobre el comercio, eliminar tasas gravosas sobre la sal, elaborar un nuevo fogaje general del reino, regular aspectos importantes sobre la aplicación de la justicia, la lucha de bandos y solucionar greujes, todo ello por acuerdos tomados por mayoría (no por unanimidad) en el seno de cada brazo, sin que el rey solicite nuevo servicio económico, que ya lo había recibido unos años antes, en las Cortes de Zaragoza de 1400
} 
en el parlamentario, y por el monarca como posible instrumento frente a la fuerza de la gran nobleza. Las actuaciones, en la década de 1370 , se produjeron en las Cortes y, por eso, el impulso dado a la "Conveniencia de los caballeros de Cataluña"8 coincidió con la exigencia baronal de segregar de su brazo a los caballeros y donceles para que en las asambleas constituyeran un círculo propio ${ }^{9}$

Los intentos de conseguirlo fueron abortados en parte por las dudas reales frente al interés de los barones, por la no clara decisión de los caballeros y por la posición contraria de la Iglesia y Universidades que se sentían perjudicados. No obstante, en las Cortes Generales de Monzón de 1383 y de 1388 , celebradas junto a aragoneses, en las que la monarquía sufrió un ataque casi generalizado que le obligó a desplegar una política defensiva en todos los frentes ${ }^{10}$, los caballeros, respaldados en la primera por la actividad del infante Juan contra su padre, buscaron ya su autonomía $\mathrm{y}$, al parecer, obtuvieron, al margen de los escasos acuerdos alcanzados en las segundas, unas concesiones por parte del monarca con el apoyo de una de las facciones de la nobleza superior que les permitió, en las posteriores reuniones estamentales (los parlamentos convocados a la muerte de Juan I hasta la llegada de Martín), deplegar una actividad corporativa muy intensa, hasta el punto de que al convocarse las Cortes en Perpiñán en el verano de 1405, se produce, al menos de forma implícita, la llamada al brazo de caballeros y donceles. De hecho, al comienzo de esta asamblea figura como portavoz del mismo don Berenguer de Olms, caballero, consejero y camarlengo real, que era, a su vez, uno de los pilares del bando encabezado

\footnotetext{
${ }^{8}$ En esta interpretación aprovecho los datos suministrados por S. SOBREQUÉS VIDAL, La nobleza catalana en el siglo XIV, "AEM", 7 (1970-71), pp. 513-531, que él toma, especialmente, de ZuRITA.

${ }^{9}$ En las Cortes reunidas en Tarragona en 1370, dentro de los episodios que marcan la propia constitución de la asamblea, se presenta por parte de los barones la petición de que los "milites et generosos" formen su propio brazo sin los ricoshombres. La oposición de los caballeros es clara, aduciendo que tradicionalmente "richishomines et milites fecerunt et faciunt unum brachium et non plus", siendo el rey, en última instancia, tras "deliberacione matura", quien decidió que "quelibet pars remaneat in suo jure sicut prius", para esa reunión y en el futuro (Cortes de los Antiguos Reinos, cit, tomo III, p. 58).

${ }^{10} \mathrm{M}$. MITJÀ, Procés contra els consellers, domèstics $i$ curials de Joan I, entre ells Bernat Metge, "Boletín de la Real Academia de Buenas Letras de Barcelona", XXVII (1957-58), pp. 375-417; J. A. SESMA MuÑoz, Todos frente al rey (La oposición al establecimiento de una monarquía centralizada en la Corona de Aragón a finales del siglo XIV), en Genèse médiévale de l'Espagne moderne: Du refus à la révolte: les résistances, Faculté des Lettres de Nice, 1991, pp. $75-94$.
} 
por el vizconde de Illa y Canet y otros nobles importantes de Cataluña" $\mathrm{y}$ en la sesión del 26 de enero de 1406, en la contestación de los estamentos a la proposición real, lo hace primero el obispo de Elna en nombre de la Iglesia, después el vizconde de Illa por los barones y, tras él, Berenguer de Olms por los caballeros y gentils homens.

Según se copia en el acta de esa sesión, mientras se producía su intervención, Juan de Sadorniu, como representante del brazo de la Iglesia, hizo entrega de una cédula de protesta porque, según los eclesiásticos, se estaba actuando como si hubiera dos estamentos de nobles, cuando siempre había sido uno; a esta acción se sumó inmediatamente Guillermo Andrés. notario y síndico de Barcelona, añadiendo que de producirse tal división los de la Iglesia y Universidades quedarían casi inútiles y la res pública sufriría un perjuicio intolerable. Tajantemente, ambos declaran que no consentían en la creación del nuevo brazo, sino que expresamente lo contradecían.

A partir de este momento el objeto de la reunión y la situación planteada por el monarca en su proposición quedaban olvidados y la discusión en las Cortes iba a concentrarse en la pretendida constitución de un cuarto brazo. La rápida suspensión de las sesiones ${ }^{12}$ decidida por Martín buscaba frenar un enfrentamiento total de los grupos por un asunto secundario durante las sesiones, apartándose él de la polémica por entender que afectaba sólo al General y que se resolvería antes dando tiempo para las negociaciones entre los más directamente implicados.

Los escritos cruzados al respecto permiten comprobar dos cuestiones: la primera, que son los brazos de la Iglesia y de Universidades los que abierta y frontalmente se oponen, por considerarlo una novedad que va en contra de las Constituciones, usos y costumbres del principado; la segunda, que detrás de los caballeros están los barones, pero más una parte de ellos $^{13}$, y posiblemente también el rey, que no duda en referirse a los caballeros como brazo, dándolo por constituido.

\footnotetext{
"Berenguer de Olms es uno de los primeros en presentarse a las Cortes y lo hace. además. portando las procuraciones de Pedro de Fonollet vizconde de Illa. de Bernardo de Cruilles. de Guillermo Hugo de Rocabertí: del conde de Ampurias, de Bernardo Galcerán de Pinós, de Geraldo Alamán de Cervelló, gobernador de Cataluña y de Bernardo de Cabrera.

'Apenas tres días después y ante la incorporación a la protesta de los representantes de las ciudades y villas.

${ }^{13}$ En la protesta de Guillermo Andrés por la intervención de Berenguer de Olms ya se deja entrever que la división del brazo está propiciada por discordias en el seno de la nobleza.
} 
La presión sobre el monarca fue tremenda como reflejo de la violencia encerrada en las posturas de los partidarios de una u otra propuesta. Las denuncias de negociaciones y manejos encubiertos fueron continuas, como la que el síndico de Lérida, en nombre de muchos del brazo real, lanzó al propio gobernador de Cataluña el 15 de marzo de 1406. en el acto de lectura del escrito real de prórroga, acusándole de estar "en representación del rey" negociando con los nobles a espaldas del resto de las Cortes, negándose a entrar a las sesiones hasta que estuviera presente el rey para decidir sobre sus protestas. En esta misma línea, para marcar diferencias, los dos brazos contrarios se denominan a sí mismos "vertaders e indubitats braços e aprovats ab antich" y el de Universidades, para resaltar su significación, adopta como título "braç real dels honorables e antichs homens donor e altres de las ciutats e viles reals del principat". Los caballeros, por su parte, aunque sin reconocimiento expreso, se autoproclaman "braç reial de cavallers i homes de paratge".

Los escritos que explican y defienden ambas posturas son largos con argumentos prolijos. Los caballeros se apoyan, según la cédula que presentan el 11 de mayo de 1406, en que "universidat, cors e collegi o braç de cavallers" es necesaria y útil, que ya existe en Cataluña, la forman los caballeros según el derecho de la tierra, que están separados de los magnates, barones y nobles y distribuidos, al parecer, en tres categorías o clases: caballeros, gentileshombres y generosos, estando reconocido el linaje de caballero. Su consideración como grupo, afirman, es muy antiguo, sin contradicción de nadie y constando por derecho, uso y costumbre de Cataluña su capacidad para actuar colegiadamente en guerra, cabalgada y aplech incluso contra barones y magnates $\mathrm{y}$, sobre todo, aducen los argumentos derivados de las intervenciones desde las Cortes de 1388, en reuniones, parlamentos y la jura del rey en Barcelona, disponiendo de voto, sello y contribución en las subvenciones, sin que los otros brazos hubieran protestado ni mostrado cualquier reticencia a negociar y actuar junto al brazo de caballeros. Todo ello, como se ve, son criterios positivos, de hechos concretos y muy pegados a la realidad y utilidad.

Por su parte, eclesiásticos y universidades plantean un primer escrito de contestación inmediata completamente opuesto, pues con una retórica basada en citas bíblicas y de autores clásicos teorizan contra los cambios y novedades en general, exaltan la solidez y perfección de lo antiguo y bien conocido y niegan la posibilidad de un brazo de caballeros. No obstante, en una segunda cédula presentada después adoptan ya la fórmula de éstos, 
buscando con precisión anular y demostrar la falsedad de los datos aportados: nunca ha habido más de tres brazos en Cataluña, ni los Usatges ni las constituciones prevén otra división, ni que se puedan hacer plegas por los caballeros contra los barones, ni es cierto que en las Cortes de 1388 se tratara de la formación del cuarto brazo y menos todavía que se aprobara ningún privilegio en ese sentido, lo mismo que el resto de intervenciones en actos posteriores.

En el escrito incorporan dos apartados muy interesantes que reflejan la mentalidad de los exponentes y el trato, un tanto despectivo, que dan a los caballeros. En uno recogen la idea de que si constituyen un colegio profesional, lo que entienden que dicen ser los caballeros, deberán haber recibido del rey el derecho de reunión para actos lícitos y honestos, así como para defender su justicia disponer de caja común y cuerpo, al menos así lo tienen los oficios de las artes mecánicas y otros servicios públicos que constituyen colegio profesional. En el otro, reconocen útil y necesario que exista orden de caballería, y así está aceptado por derecho divino y humano, siempre que se base en: "leugeria, fortalesa, disciplina darmes, ornament de bones costumes, honestat, ardiment sens pahor sino de mala fama, strenuitat, saviesa, ferocitat, no afeminats, no deliquats, no pauruchs, tolerants los temps tempestuoses, reposants en terra, traball e fretura en un mateix temps sofirents, jurats que strenuament faran ço que a ells per lur princep e senyor sera manat e que no desempararan cavalleria ne squivaran mort per la cosa publica, la sgleya de Deu deffendran, perfidia impugnaran, sacerdoci honraran, la injuria dels pobres propulsaran, la cosa publica reposada e pagada tendran". No parece que para eclesiásticos y burgueses los caballeros catalanes de comienzos del siglo XV reunan estas condiciones y aporten estos servicios.

Evidentemente, el asunto no tenía una solución fácil. La única salida era política y su búsqueda exigía una firmeza del rey que a todas luces no estaba en disposición de aplicar ${ }^{14}$. La evasión que significaba las continuas prórrogas ${ }^{15}$ no sirvieron más que para incorporar argumentos y posturas cada vez más extremas. En la refriega se llega a dudar de que la reunión sea

\footnotetext{
${ }^{14}$ Como la actuación de Pedro IV en las Cortes de Tarragona, vid. nota 9.

${ }^{15} \mathrm{El}$ rey, a su vuelta de Valencia, se refugia en el Palacio Real de Barcelona y deja que su protonotario o su procurador fiscal maneje las prórrogas y atienda las protestas.
} 
realmente de Cortes $^{16}$; se acusa al rey de incapacidad para resolver los problemas serios que afectaban a Cataluña ${ }^{17}$, se le reclama, por el síndico barcelonés, ejerza "vostre offici real que es per justicie tolre debats e provehir als scandols e perills sdevenidors" y, sobre todo, se despliega un fuego cruzado entre los brazos que muestra la ruptura en el seno de la clase política de Cataluña ${ }^{18}$.

Los capítulos de una concordia finalmente presentados por el rey para salir del estancamiento a que había llegado la asamblea a mediados de 1408 se basan en dejar en suspenso la cuestión de los caballeros y sin negar sus razones ni los de los otros dos brazos que se oponen, proceder a tratar los actos de interés general relativos al bien común y público, para lo cual propone la constitución de una comisión de 28 miembros -8 pertenecientes y elegidos por el estamento de la Iglesia, otros tantos por el de Universidades y 12 por el de barones, nobles, caballeros y hombres de parático-, así como otras subcomisiones que siguiendo un procedimiento complejo recibían plena potestad para llegar a acuerdos con los comisionados por el monarca. Tras su presentación el 27 de junio de 1408 y a propuesta de los brazos, el rey traslada las Cortes a Barcelona para el 4 de julio próximo, declarando, además, levantada la contumacia para todos los que no habían acudido y abriendo, con ello, la posibilidad de presentarse todos los que tuvieran derecho a hacerlo.

La falta de decisión de Martín para llevar adelante su criterio, la obligación impuesta al brazo militar de elegir entre todos sus componentes

${ }^{16}$ El 27 de junio de 1408 el abad de Poblet como portavoz de los brazos, pide que para tranquilidad de todos "sie declarat la dita present Cort esset Cort vertadera e haver subsistencia e valor de Cort", lo que hace inmediatamente el rey.

${ }^{17} \mathrm{Con}$ anterioridad a lo manisfestado por el abad de Poblet, el 29 de marzo, el caballero Juan de Montbou, en su nombre y en el de otros del brazo militar, presenta un escrito a "la present Cort, on Cort puxa esser dita", acusando al rey, por su ausencia prolongada. de ser causante del perjuicio a la cosa pública y de los grandes gastos de los convocados, reclamando atienda las cuestiones graves padecidas: la casa real está en mala situación y no tiene el orden que corresponde, la honor real no es reconocida ni dentro ni fuera del reino, existen desarreglos de justicia, con división de bandos, guerras, muertes e infinitos escándalos: como gracias a Dios, termina el escrito, sus otros reinos están "consolats de Cort e de justicia e de regle" y el rey ha regresado a Cataluña, le suplica se persone en las sesiones y continúe las Cortes para alcanzar la reparación de la res publica.

${ }^{18}$ Por ejemplo, el representante de los caballeros, el 31 de marzo de 1408 , declara que las universidades reales no deben ser admitidas como brazo en las Cortes, ni en ninguna otra manera, pues asisten porque antiguamente se permitió su entrada graciosamente, pero sin tener ningún derecho a ello, lo mismo que algunos prelados y capítulos eclesiásticos que tampoco tienen derecho para constituir brazo. 
unos representantes con autonomía en las negociaciones y la cuña introducida con la declaración que permitía la incorporación de nuevos miembros y procuradores a unas sesiones que se trasladaban a Barcelona, no cerraban el debate sobre el primer punto de fricción, sino que abrían nuevos frentes de discusiones y protestas, preparando el terreno para manifestarse la más grave fractura entre los asistentes: la profunda escisión de la nobleza en dos bloques, incompatibles en sus planteamientos, cuyo origen se remontaba, al menos, al final del reinado de Pedro IV.

\section{LOS DOS BANDOS DE LA NOBLEZA CATALANA}

Resulta elocuente que los únicos asistentes del brazo militar en las sesiones reiniciadas en Barcelona el 4 de julio, el vizconde de Illa y Canet y Bartolomé de Vilafrancha, doncel, comienzan su actuación con una postura abiertamente contestataria. Se niegan a poner en marcha los capítulos de la concordia real mientras no se repare el asunto de los procuradores que están indebidamente incorporados y aunque ponen como gran pretexto el excesivo número de síndicos enviados por Barcelona (hasta 8$)^{14}$, sus referencias ocultas iban dirigidas a ciertos miembros de la nobleza que por estar al servicio del rey o no haberse presentado en su momento no debían ahora ser recibidos ${ }^{20}$. La protesta, además de por escritos, la manifiestan permaneciendo en pie durante las sesiones, llegando tarde a sus escaños y, por supuesto, no realizando la elección de los miembros de su grupo que debían configurar las comisiones de trabajo.

En este ambiente y con la oportunidad que podemos imaginar, el rey decide intervenir en la asamblea y solicita ayudas económicas: un préstamo para poder desarrollar su actividad real, ya que carece de medios incluso para recibir dignamente a los enviados castellanos, y subvención urgente

\footnotetext{
"También los acontecimientos de Barcelona reflejan la situación de inestabilidad social. vid. M.T. Ferrer I MALLOL. Lluites de bindols a Barcelona en temps del rei Marti l'Humà. "Estudis d'Història Medieval". I (1969), pp. 77-94

"De hecho, en la sesión del 23 de julio por la tarde. el vicecanciller hace pública en las Cortes que ambas partes que han parcipado en el debate sobre la admisión de los sindicos de Barcelona han acordado dar por no presentadas las cédulas de protesta que hasta ese día se habian aportado, y él las declara como no insertas en el proceso y. por tanto. "sobre lo dit debat les dites parts sien en certa forma concordes". Io que no impide que el vizconde de Illa. Bernardo Galcerán de Pinós "et aliorum sibi adherencium" sigan protestando y expresando una clara oposición a todo lo que en la asamblea se trata.
} 
para la campaña militar en Cerdeña que encabezada por su hijo Martín, rey de Sicilia, consiga pacificar a los rebeldes sardos. Así consigue canalizar los debates, pero no resolver los problemas.

La contestación de las Cortes a la subvención para la guerra en las islas se produjo en la sesión del 28 de julio, por boca del prior de Cataluña, y fue categórica y, al parecer, unánime: no podían ayudarle porque sería quebranto de sus libertades. La insistencia real, rogando (casi podemos decir que suplicando) auxilio para el primogénito llevó a los brazos a tomar una decisión que muestra claramente el juego de componendas seguido por los distintos grupos y el rey: las Cortes acuerdan el envio de una embajada propia al rey de Sicilia y, como protección debido a que "les mars no son segures", se harán acompañar de cuatro naves y seis galeras armadas: dejan claro que no es una aportación a la guerra, ni una subvención, ni un acto que pueda traerse en el futuro como precedente y que los gastos se financiarán con dinero obtenido por los diputados mediante la emisión de censales cargados sobre el General. Al mismo tiempo, las Cortes suplican al rey que dicte tregua en el principado entre los hombres de condición militar y seguridad entre los de pie para que el territorio esté tranquilo y en paz.

A partir de este momento, la atención de los reunidos, en número importante en cada sesión ${ }^{21}$. iba a converger en dos asuntos: la puesta en práctica de la embajada aprobada al rey de Sicilia y la composición de las comisiones que intentaran alcanzar acuerdos en los temas comunes. En ambos, las matizaciones y precisiones daban de sí suficiente materia para que se pudieran discutir largamente, sobre todo cuando no existía especial interés por el resultado y, en cambio, sí de utilizarlos como pretexto para combatir al bando contrario. A partir de este momento y hasta el final de la reunión se pondrá de manifiesto la existencia de dos criterios muy distintos entre los miembros del brazo militar, expresados por la formación de dos bandos enfrentados, que implacablemente utilizarán todos los argumentos para demostrar la escasa capacidad y mala voluntad del otro en la solución de los problemas y, de paso, impedir cualquier acuerdo.

El primero de ellos estaba encabezado por Pedro de Fonollet, vizconde de Illa y Canet, presente en las sesiones, muy activo en todo

\footnotetext{
"Como muestra aplicable a muchas sesiones. a la del dia 3 de agosto de 1408 asistieron 15 miembros de la lglesia. 11 nobles. 13 caballeros, 4 donceles y los sindicos de 17 ciudades.
} 
momento y acompañado constantemente del caballero Berenguer de Olms. Sus escritos son precisos, exponiendo unas posturas ante los temas planteados en que siempre reivindican la necesidad de hacer bien las cosas, de acuerdo con la legalidad, buscando la utilidad y evitando caer en la rutina; quieren siempre aparecer como garantes del orden y la dignidad y buscando el bien común. Se trata de un grupo muy numeroso, que cuenta en su seno con representantes de la gran nobleza entre los que destacan los condes de Prades y Pallars, los vizcondes de Castellbó, Perelló y Rocabertí (su tutor), Bernardo Galcerán de Pinós, Luis de Abella, Acardo de Mur y una larga serie de apellidos unidos a la caballería más tradicional o con mayor futuro: Oluja, Peramola, Requesens, Ça Cirera, Ça Rocha, Boxadors, etc. ${ }^{22}$

La otra "adherencia", "vulgariter dicta comitis Urgelli", tiene a su frente al conde de Urgel, casi siempre representado por un procurador - figuran varios con tal encargo-, actuando como portavoz el noble Arnaldo Guillermo de Bellaria, doncel, o el caballero Antonio Torrelles y, en la última parte de las sesiones, el conde de Cardona que, sin embargo, aparece inicialmente en la lista de adheridos al grupo del vizconde. Sus actuaciones son mucho más torpes, sin que aparezca clara la postura colectiva, dándose ocasiones en las que el apoderado del conde se ve obligado a posponer su respuesta hasta haber consultado con su principal ${ }^{23}$, aunque los otros se hubieran pronunciado ya; en general muestran una tendencia a atender las peticiones del rey y a defender con decisión los procedimientos establecidos y sus prioridades. A juzgar por la propia nómina aportada ${ }^{24}$, el respaldo nobiliar es menos numeroso y cualitativamente menos relevante, pues no solo estaba constituido en su mayor parte por donceles, sino que no está muy claro que los pocos nobles incluidos estén realmente y con todas las consecuencias, pues en el escrito presentado por el vizconde de Illa para rebatir la fidelidad de estas procuraciones se dice claramente que entre todos no son sino 45 , y de ellos hay una docena de oficiales con jurisdicción real en ejercicio que no son hábiles para participar en Cortes, otros no son

\footnotetext{
"2Vid. al final, Apéndice I.

23" Jo Johan de Pinell dich que noy assent ney dissent tro a tant que hage consultat lo senyor Comte mon principal".

${ }^{24}$ Vid. al fïnal, Apéndice II.
} 
habitualmente convocados y "ha molts qui son jovens sterles e no cathalans ne heretats en Cathalunya".

Esta es una de las razones aducidas para que continuamente el partido del vizconde de Illa no consienta en ninguno de los actos emprendidos por el brazo "hasta que sean expulsados aquellos que no deben intervenir", colapsando cualquier decisión e impidiendo con la simple objeción de que "nosaltres no consemtim en res que aci sia feyt per los altres barons e cavallers, ans expressament hi dissentim" que se emprendan muchos actos. No obstante, el grupo del de Urgel parece tener detrás la voluntad real y ello hace que poco a poco y por el simple procedimiento de ir aparcando las propuestas no deseadas e introduciendo en las comisiones una mayor representación de la facción deseada, la oposición vaya perdiendo fuerza, bien es verdad que al mismo tiempo se van debilitando las propias Cortes y finalmente, tras el fallecimiento del príncipe Martín se diluye la asamblea en la inoperancia, deseando todos -el rey casi no vuelve a aparecer - encontrar una fórmula para la disolución ${ }^{25}$ que suponga una salida digna. Evidentemente, la muerte del rey significa, máxime sin contar con sucesión decidida, la clausura inmediata de las sesiones.

\section{LOS ENFRENTAMIENTOS ENTRE LOS DOS BANDOS NOBLES}

El comportamiento y las posturas adoptadas por ambos bandos de la nobleza condiciona la evolución de las Cortes, sin que se aprecie realmente la intervención de los otros dos brazos. El debate de mayor contenido de los suscitados en el proceso es, sin duda, el provocado por la solicitud de ayuda por parte del rey para la intervención en Cerdeña; de la forma de afrontarlo y de los planteamientos expuestos allí podemos captar las diferencias existentes entre los dos partidos y la ruptura que suponen en el seno del bloque militar de Cataluña.

\footnotetext{
${ }^{25}$ Con motivo de la epidemia de peste que se declara en diciembre de 1409 se vuelve a producir un enfrentamiento de posturas, pues el brazo militar quiere el traslado en contra de la opinión del brazo de universidades, quizá como una réplica del debate anterior, ya que su salida de Barcelona haría más costosa a la ciudad mantener el elevado número de procuradores que tenía: dentro, no obstante, del estamento noble, los dos bandos tampoco están totalmente de acuerdo, pues Berenguer de Olms insiste en el cambio para preservar la salud del rey, y quizá de paso aislarle del entorno ciudadano, mientras que Antonio Torrellas y los del conde de Urgel protestan por tal petición. Finalmente el monarca no ve preciso moverse. Vid. al final, Apéndice II.
} 
Las constantes acusaciones, cada vez menos veladas, lanzadas por el bando urgelista contra los del vizconde, señalándoles como los culpables de las dificultades para enviar el auxilio al infante Martín, tienen como origen la postura de éstos ante. lo que suponen, manejos del rey al margen de la asamblea para convertir la embajada en una subvención encubierta. La decisión del grupo, mientras la mayoría responde hoc, hoc, es de plantear, con seriedad y argumentos, la imposibilidad de hacer actos de Corte fuera de las sesiones y denunciar el uso descontrolado del dinero recaudado por el General, cuya responsabilidad es de los Diputados y éstos dependen exclusivamente de los brazos de las Cortes ${ }^{26}$.

Poco después, en la sesión vespertina del 14 de diciembre de 1408 , ofrecen un escrito contestando al entregado cuatro días antes por el conde de Cardona en su nombre y en el del procurador del de Urgel, del vizconde de Roda, de Pere de Montcada, de Arnau Guillem de Bellera y de otros adherents a ells, lleno de frases grandilocuentes, denunciando la falta de colaboración de una parte del grupo militar (alguns singulars) y manteniendo la vía fácil de financiar la embajada/expedición con dinero público del General, a lo que frontalmente se habían opuesto el partido del vizconde ${ }^{27}$. La propuesta de éste, avalada por el vizconde de Castellbó, Roger Bernardo de Pallars, Bernardo Galcerán de Pinós y de los barones y caballeros de lur adherencia, se resume en tres puntos:

1. Como es sabido, los barones y caballeros de Cataluña están exentos de hacer subvención en conquistas o necesidades de las islas.

\footnotetext{
2hen los escritos de 13 y 21 de noviembre de 1408 denuncia las maniobras llevadas a cabo por el rey fuera de las Cortes con la complicidad de los que se han erigido como representantes de los barones, privando del derecho que todo barón. caballero y gentilhombre del principado tiene de asistir e intevenir en las Cortes durante todo su proceso "e dir son vot e francha oppinio en tots actes": de hacer actos de Corte fuera de las sesiones de Cortes: haber presentado albaranes a nombre de las Cortes por valor de 21.000 thorines sin haber recibido autorizacion para ello ni haber decidido la asamblea las partidas. Eclesiásticos. universidades y Arnaldo Guillem de Bellaria en nombre de su partido, se muestran. de inmediato. disconformes con el contenido.

${ }^{27}$ El dia 7 de diciembre de 1408, en una sesión tumultuosa, los vizcondes de Castellbó y de Illa. en nombre de Roger Bernat de Pallars. Bernat Galcerán de Pinós. Pere de Sentmenant como procurador de la reina Violante. Berenguer Arnau de Cervelló, Berenguer de Olms. Bartolome de Vilafranca como procuradores de los condes de Prades y Pallars, de Bernardo de Cabrera. del vizconde de Rocabertí y de otros muchos, habian revocado la autorización otorgada a los Diputados del General para emitir 100.000 florines en censales, por creer. y aportan datos concretos. que se están produciendo muy serias irregularidades en la administración del dinero. anunciando que se opondrán por todos los medios a que en sus tierras se proceda en lo sucesivo a la recaudación de los impuestos del General.
} 
2. En consideración del esfuerzo y sacrificio del rey y del primogénito, están dispuestos a tratar de la ayuda confiando, y exigen garantías del rey, que luego se abordará la solución de los greuges y se procederá a dar satisfacción a los asuntos de la justicia, para lo que se habían convocado las Cortes.

3. Recogiendo lo dicho por el conde de Cardona "e los de sa adherencia, quis affermen esser la maior part de les condicions del barons e cavallers de Cathalunya" en su anterior escrito y para demostrarlo querrán tomar a su cargo el envío de tantas gentes de armas como ahora ellos están dispuestos a ofrecer, han decidido correr "de lurs béns propris" con la mitad de los gastos que suponga levantar el ejército solicitado por el primogénito para su intervención corsa, 1.500 de caballo y 3.000 peones armados durante cuatro meses, para que así no sea necesario cargar al General y el dinero recaudado pueda servir para reducir la deuda. De esta forma, concluyen, se conocerá y demostrará lo que vale cada uno y quien está dispuesto a servir lealmente y con prontitud.

Esta propuesta coge por sorpresa al bando contrario que sólo puede contestar, por boca del conde de Cardona: "Mossèn, per tant com nosaltres no havem encara deliberat car speravem que la resposta se fahés en concòrdia de tots los de nostra condició, vos responem que dilluns si plaurà a Déu nosaltres havrem delliberat e farem nostra bona resposta".

A pesar de esta promesa, no se vuelve a tratar el tema en sesión de Cortes hasta que el 15 de enero siguiente, cuando los vizcondes de Castellbó e Illa en nombre de los suyos, presentan un nuevo escrito, algo distinto a los habituales, muy retórico, con profusión de citas clásicas y con un pensamiento político regalista, con exaltación de la figura del rey, aludiendo a sus gloriosos predecesores que conquistaron Cerdeña y que, como hará el primogénito, hicieron "flameiar les banderes victorioses d'Aragó fúlcides e ornades de molts excelsos e antichs barons e cavallers", confirman su ofrecimiento, pero aportando ellos solos los 1.500 hombres de caballo y 3.000 de pie por cuatro meses, necesarios para la batalla que se espera en la isla en la primera semana de mayo; para confirmar su proposición copian la nómina de los nobles que se ofrecen a participar ${ }^{28}$. No obstante,

\footnotetext{
${ }^{28}$ La lista está encabezada por el vizconde de Castellbó acompañado de uno, dos o tres hermanos suyos y otros 15 entre barones y nobles, además de muchos caballeros y gentilhombres. Sigue el vizconde de Illa y Canet. Roger Bernardo de Pallars, Bernardo Galcerán de Pinós. Galcerán de Castro. Berenguer Arnau de Cervelló, Bernardo de Cruilles, Guillem Hugo
} 
lamentan, que ni el rey, ni el príncipe, ni las Cortes hayan aceptado la oferta anteriormente hecha y se siga tratando del envío de la embajada, por lo que si en el plazo de tres días no obtienen una respuesta, la retirarán y se considerarán liberados de cualquier cargo y de la responsabilidad de lo que suceda.

El protonotario, en nombre del rey, se apresura a contestar que ya hace días que se cursó la aceptación "a la gran e bella oferta feta per lo vezcomte de Castellbó ...", si bien no puede garantizar el cumplimiento de sus condiciones, pues depende de la voluntad de las Cortes. La fría respuesta hace comentar a Berenguer de Olms: "Nosaltres no som certs de la dita responsa jatsia la haiam demanada al scrivà". Mientras, la adherencia del de Urgel pide copia de la oferta y dos nobles, Bernardo de Cruilles y Ramón Xatmar se desmarcan de lo ofrecido y piden ser tenidos por no nombrados.

En lo sucesivo ya no vuelve a figurar el asunto, sino que siguen los trámites para la venta de censales cargados sobre el General, por trescientos mil florines, para atender préstamos al rey, en algún caso exigiéndole el depósito de las rentas de determinadas posesiones reales como garantía ${ }^{29}$, y para atender los gastos de una embajada que al parecer no se llegó a efectuar. Todo ello se aprueba por mayoría ("multum placebat et aliqui ex eius minime contradixerunt"), apareciendo siempre como objetores el grupo nobiliar representado por el vizconde de Illa y Canet, que a pesar de contar con respaldo mayoritario de la nobleza catalana, tiene un peso muy limitado en la actuación de su brazo y el rey se apoya más en el bando urgelista.

\footnotetext{
de Rocabertí, Bernardo de Forciá, Luis de Perelló, Guillem de Só "e altres barons e nobles que per causa se ommeten", cada uno con cierto número de caballeros y gentilhombres. Luego Ramón de Bagues, Berenguer de Olms, Franci Ça Cirera, Macia dez Puig, Francesch Bellcastell, Francesch de Vallgornera, Ramón Xatmar, Pere de Sentmenant, Jaime de Ribes, Guillem de Rajadell, Ramón dez Brull, Francesch Taverner, Ramón de Boxadors, Bernardo de Requesens, Bartolomé de Vilafrancha, Bernardo de Muntpalau, Juan dez Far, Marc de Avinyó, Dalmau de Castellbisbal, Jaime de Tagamanent "e molts altres cavallers e gentilshomens que a present se ommeten", cada uno con cierto número de gentilhombres.

${ }^{29}$ Para los 105.000 florines prestados en marzo se exige la entrega de las rentas del condado de Ampurias, que después de una larga negociación, cerrada el 29 de dicho mes, se concreta en las villas y castillos de Cadaqués, Rosas, Lançá, Ampurias, Garriguella y su bailía, el monte de San Pedro de Rodas, con sus términos y jurisdicción alta y baja. El 16 de agosto de 1409 el rey suplica un préstamo de 50.000 florines, volviendo a solicitarlo el día 28; la contestación de las Cortes se produce el 30 , siendo afirmativa con las siguientes condiciones: debe dejar bienes suyos por igual valor en poder de las Cortes, deberán administrarse por personas puestas por el rey y las Cortes, cesarán las exacciones efectuadas anteriormente en dominios de la Iglesia y en las Universidades, expoliadas por diversos conceptos (coronajes, mulierajes, etc.), resolución de greuges, etc.
} 


\section{EPÍLOGO}

En este clima prolongado durante casi cinco años, se producen, sucesivamente, tres acontecimientos decisivos para la evolución política de Cataluña y de la Corona. El primero, el fallecimiento del primogénito; el segundo el rápido matrimonio de Martín para buscar heredero y, finalmente, la muerte del propio rey consumando la falta de un sucesor.

En el plazo de unos meses, las graves carencias de entendimiento manifestadas en las Cortes por los grupos rectores de la sociedad catalana se verán ante el enorme dilema de decidir la sucesión del rey. Los mismos que habían sido incapaces durante años de ponerse de acuerdo para la simple constitución de una comisión que decidiera los problemas de la justicia, no habían estado dispuestos a aceptar una modificación en la forma de participación de las propias minorías dirigentes en las Cortes y ni tan siquiera querían comprender el daño inflingido al conjunto de la sociedad con la alegre emisión de deuda pública para financiar campañas militares en el exterior, entre otras cosas, deben encargarse de afrontar un interregno.

La única cosa clara que parece desprenderse es que el asunto les parece demasiado importante para abordarlo únicamente desde Cataluña y, desde el principio, estiman preciso la participación de toda la Corona. Así, cuando tras la muerte del príncipe el rey pide consejo "a las Cortes en los affers e conservació de Serdenya e de Sicília", sin mencionar otras cuestiones, la asamblea, de manera muy delicada recomienda, no sólo para esos asuntos, sino para los que se refieren a Cataluña y a los otros reinos del monarca, la convocatoria urgente ("promtement e sens tarda") de un parlamento general que permita a todas las Cortes juntas buscar el consejo que sea en "excalçament a la sua Reyal Corona e profit a sos regnos e terres".

Esta idea será la que tras la muerte del rey se ponga en práctica. Y de la misma forma que no ofrece dudas el mecanismo seguido a partir de aquí, hay que considerar que la fractura de la clase política catalana tan . crudamente mostrada en el proceso de estas largas Cortes, coñ las profundas diferencias entre los caballeros y las ciudades y entre la nobleza partidaria del conde de Urgel y el bloque aglutinado por los vizcondes de Illa y Castellbó, jugó un papel definitivo y, de hecho, el resultado final adoptado 
en Caspe $^{30}$ y las consecuencias arrastradas a lo largo de la centuria en Cataluña fueron debidas a la ruptura padecida por la propia sociedad catalana, mucho más que a la imposición exterior de nadie.

${ }^{30} \mathrm{El}$ tema del interregno y del Compromiso de Caspe debería ser objeto de un profundo estudio, pues todavía está teñido de muchos tópicos e interpretaciones poco científicas. Es lamentable que sigamos sin querer hacer historia de la Corona de Aragón. 


\section{APÉNDICE I}

Relación de barones y caballeros de Cataluña que suscriben la cédula presentada en las Cortes del Principado en la sesion del l de octubre de 1408, por el vizconde de Illa y Canet, "nomine suo et suorum adherencium".

Los noms del presentats son mossen Pere de Fonollet, vezcomte de Illa c de Canet, Bernat Galceran de Pinos, mossen Bernat de Forcia, Pedro Galceran de Castro, mossen Francesch Taverner, Berenguer d'Olms, Pere de Sentmenat, cavallers, Galceran d'Uluja, en noms lurs propris e lo dit Pere de Sentmenant com a procurador de la senyora reyna dona Yolant, e lo dit Berenguer d'Olms com a procurador del noble mossen Bernat de Cabrera; Johan de Miralles, procurador del comte de Pallars, Arnau de Santa Coloma, procurador del vezcomte de Castellbo, Arnau de Montanyans, procurador del noble mossen Berenguer Arnau de Cervello.

E ells dits vezcomte de Illa, Bernat Galceran de Pinos, Berenguer d'Olms, Pere de Sentmenant y Galceran d'Uluja, en noms lurs propris e com a procuradors ensemps $\mathrm{e}$ in solidum ab altres':

Abella, noble mossen Luys d'

Aguilar, en Guillem d'

Alamany de Bellpuig, en Jacme

Amoros, en Pere

Ampuries, Guillem d'

Aranyo, mossen Barthomeu

Areny, en Bernat d'

Areny, en Phelip d'

Argençola, en Pere d'

Aroles, en Roger d'

Avinyo, en Galceran d'

Avinyo, Guillem d'

\author{
Avinyo, en March d' \\ Banyulls, en Dalmau de \\ Barbera, en Bernat de \\ Batle, Pere \\ Bellars, Jorda de \\ Bellars, Pere de, son fill \\ Bellcastell, en Franci de \\ Biure, Arnau de \\ Boscarons, en Gilabert de \\ Boxadors, en Berenguer de \\ Boxadors, en Johan de
}

\footnotetext{
1 He optado por ordenar alfabéticamente la larga lista de nombres transcrita seguida en la edición de la Real Academia. He mantenido las grafías. el tratamiento y todas las aclaraciones aportadas en el texto.
} 
Boxadors, en Ramon de

Brull, mossen Ramon dez

Ça Cirera, en Bernat, fill de mossen Jacme Ça Cirera

Ça Cirera, en Dalmau, fill de mossen Guillem Ça Cirera

Ça Cirera, en Guillem, fill de mossen Maymo Ça Cirera

Ça Clusa, Barthomeu, son fill [de Ponç]

Ça Clusa, Ponç

Ça Corbelia, en Andreu

Ça Costa, en Francesch

Ça Costa, en Anthoni

Ça Rocha, Anthoni

Ça Rocha, mossen Berenguer

Ça Rocha, en Pere

Ça Rochafort, en Pere

Ça Sella, en Ramon Dalmau

Cadell, en Pere

Calders, en Galceran de

Calders, en Pere Galceran de

Calders, en Ramon de

Camporrells, en Anthoni de

Canadal, Guillem de, fills del dit Pere de Canadal

Canadal, Pere de

Canadal, Pere de, maior de dies

Canadal de Figueres, Ferrer de

Canadal de la Jonquera, Bernat

Canadal de Vilarnadal, Pere de

Canet, en Dalmau de

Caramany de Pinos, noble mossen Jordi de

Cardona, v. Comte de y Francisquina

Cartella, Roger de

Cassa, Uguet de

Castell, Pere

Castellauli, en Ramon de
Castellbisbal, en Dalmau, menor de dies

Castellbisbal, en Roger de

Castellbo, v. Vezcomte de

Castellet, en Ferrer de

Castellvi, en Asbert de

Castellvi, en Berenguer de

Castllar, en Ponç dez

Castllar, Ramon dez

Castro, noble don Pedro Galceran de

Çator, en Bertran

Caxas, Berenguer de

Comenge, en Bertran de

Comes, en Pere ces

Comte de Cardona, don Johan Ramon Folch

Comte de Pallars, don Huch

Comte de Prades, egregi en Johan

Copons, en Berenguer de

Copons, en Huguet de

Copons, en Huguet de (El nombre aparece dos veces en la lista en distintos lugares).

Corbera, mossen Riambau de

Corrego, en Galceran de

Cortit, mossen Pere

Corvella, Guillem de

De So, noble mossen Guillem

Despaen, Guillem Ramon

Fallo, en Johan de

Ferrer, en Guillem, senyor de la Mora

Ferrer, en Johan

Foix, mossen Johan de, v. Vezcomte

- de Castellbo

Folch, don Johan Ramon, v. Comte de Cardona

Fonollet, noble mossen Anthoni de

Fontcuberta, mossen Ramon de 
Francisquina, noble dona na, muller del noble don Hugo de Cardona, quondam, en nom seu propri e com a tudriu e curadriu testamentaria ensemps ab lo noble don Pedro de Cardona, dels nobles en Ramon e Aldonça, pubills, fills dels dits don Hugo e dona Francisquina.

Fuxa, mossen Arnau de

Gallart, Francesch, maior de dies

Gallart, Francesch, son fill

Galliners, Pere de

Gancelm, en Jordi

Gaver, en Galceran de

Giner, en Johan

Giner, en Pere

Granell, en Ramon, senyor de la Corbella

Gualba, en Ponç de

Gualta, Bernat de

Guimera, en Bernat de

Guimera, mossen Gispert de

Ivorra, en Guillem

Jafer, Guillem de

Josa, en Dalmau de

Josa, noble en Guillem Ramon de, fill del noble mossen Guillem

Ramon de Josa

Josa, en Pere Ramon de

Limos, Bernat

Loret, Guillem Ramon de

Luppia, alias de Bages, mossen Ramon de

Luria, mossen Alfonso de

Malla, en Berenguer de
Malla, en Ponç de Margarit, mossen Bernat Maya, en Luys de Miralles, en Johan de Mont, Guillem dez Morell, en Berenguer Arnau de Muntagut, mossen Berenguer de Muntboy, mossen Johan de Muntçonis, en Arnau de Muntoliu, en Bernat de Muntpaho, en Leonart de Muntpalau, en Bernat de Mur, noble mossen Acard de

Olms, en Arnau d'

Olms, en Ot d', alias Pastorets

Olms, en Pere Arnau d'

Orcau, en Tristany d'

Orenga, en Bernat d'

Oriz, en Berenguer d'

Oriz, en Johan d'

Palau, Berenguer de

Palou, Dalmau de

Palou, Guillem Arnau de

Pallars, v. Comte de

Pallars, en Huguet de

Pallars, en Roger Bernat de, fill del dit Comte de Pallars

Parapertusa, en Bernat de

Pau, mossen Pere de

Peguera, mossen Andreu de

Peguera, en Guillem de

Peguera, en Johan de

Peguera, noble mossen Ramon de

Peramola, en Pere de

Pere, Bernat

Perellos, v. Vezcomte de

Perez de Resa, Gil

Pinos, noble en Bernat Galceran de

Pinos, mossen Guillem de 
Pontos, Berenguer de

Pontos, Dalmau de

Pontos, Luys de

Prades, v. Comte de

Puig, mossen Macia dez

Puigserver, en Cervero de

Pujades, en Bartholomeu ces

Queralt, en Pere de

Rabinat, en Gispert de, senyor de Malacara

Requesens, mossen Bernat de

Requesens, mossen Luys de

Ribelles, noble mossen Ponç de

Ribes, en Franci de

Ribes, mossen Jacme de

Rochaberti, v. Vezcomte de

Rochaberti, noble en Guillem Huc de

Rochaberti, noble mossen Guerau de

Rochabruna, Dalmau

Sanserni, en Ramon de

Sant Just, en Asbert de

Sellent, en Arnau

Sent Marti, en Dalmau de

Sent Miquel, en Arnau Pere de

Sent Miquel, Bernat

Soler, Dalmau

Talarny, en Jacme

Tamerit, en Bernat de

Taverner, mossen Francesch

Thous, en Bernat de

Torroella de Ullan, Bernat

Uluja, en Galceran d'

Uluja, en Jacme d', senyor de Tudela

Uluja, en Pere d'

Uluja, Ponç d'

Uluja, en Ramon d'
Uluja, en Ramon d', frare del dit Jacme d'Uluja

Uluja de Lorach, en Berenguer d'

Uriachs, en Ramon Bernat d'

Vall, en Bernat dez

Vall, en Matheu dez

Verg, Anthoni den

Vezcomte de Castellbo, mossen Johan de Foix

Vezcomte de Perellos, noble mossen Ramon

Vezcomte de Rochaberti, noble en Dalmau

Vilafrancha, en Bartholomeu de

Vilafrancha, en Bertran de

Vilafrancha, en Roger de

Vilagut, Bernat

Vilalonga, Francesch de

Vilamari, Berenguer de

Vilamari, mossen Johan de

Vilamari, Johan de, fill del dit mossen Johan de Vilamari

Vilamari, Pere de

Vilamur. en Guillem de

Vilarig, mossen Bernat de

Xatmar, mossen Ramon 


\section{APENDICE II}

Relación de componentes de la condicion militar que son adheridos al conde de Urgel y confirman la cedula presentada a las Cortes el dia 2 de octubre de 1408 por Johan Pinell, procurador del conde y mossen Anthoni Torrellas, como procurador $d e^{2}$ :

Benviure, mossen Pere de

Bertran, mossen Francesch, cavaller

Bertran, en Anthoni, fill seu, donzell

Ça Clusa, en Bernat, donzell

Canet, en Dalmau de

Canyelles, en Johan de

Castellauli, en Guillem Ramon de

Celada, en Johan

Clariana, en Pere de, donzell

Clariana, en Pere Galceran de, donzell

Colomer, en Huguet dez, donzell

Cruylles, en Guerau de, donzell

Far, en Huguet dez, alias Lança

Far, en March dez, alias Lança, donzell

Gravalosa, en Ramon de, donzell

Gurb, en Francesch de, donzell

Jardi, en Dalmau de, donzell

Lobets, Johan
March, en Luys

Merles, mossen Pere de, cavaller

Muntanyans, en Guillem de

Muntanyans, Johan de

Olzinelles, en Johan de

Olorda, mossen Guillem Pere de, cavaller

Oriz, en Johan d'

Perellos, vezcomte, v. Soler, Dalmau dez.

Palau, en Guerau dez, donzell

Planella, Johan de, donzell

Requesens, Uguet de, menor de días, donzell

Rexach, en Galceran de

Rosanes, en Bernat de, donzell

Rosanes, mossen Galceran de, cavaller

Rosanes, en Galceran de, donzell

Rosseta, Pere

Sarria, en Pere de

Semahuja, en Guerau de, donzell

\footnotetext{
actas.

'Igualmente, sólo se ha procedido a poner en orden alfabético la nómina transcrita en las
} 
Soler, Dalmau dez, en nom propri e com a procurador de mossen lo vezcomte de Perellos

Soler, en Francesch dez

Tora, Francesch

Torrelles, en Manuel de

Torrelles, Ramon, senyor del castell de Rubi
Vezcomte de Perellos, v. Soler,

\section{Dalmau dez}

Vilademany, en Bernat de

Vilafrancha, Pere de

Vilalba, en Guillem Sabria de

Vilalba, en Pere de, donzell

Vilanova, mossen Asbert de, cavaller

Vives, mossen Francesch Johan, cavaller

E altres a ell adherents e adherir volents, los nobles mossen Pere de Muntcada, mossen Galceran de Santa Pau, mossen Arnau Guillem de Bellera, mossen Gilabert de Canet, cavaller, mossen Francesch de Vilanova, mossen Gilabert de Canet, mossen Guerau Alamany de Toralla, en nom lur propi e de tots aquells qui seran a ells e son adherents.

\section{RÉSUMÉ}

Durant les cinq années qui précedèrent la mort du Martin I, aux Assemblées réunies de Perpignan, Sant Cugat et Barcelona, les groupes privilégiés de la Catalogne se virent confrontés quant à la conception politique de la Principauté. Ceci empêchait tout progrès et reflétait une rupture entre les membres de la noblesse et ceux de la cavalerie ce qui explique la défaite du Comte d'Urgel à la succession au trône de la Couronne d'Aragon.

\section{SUMMARY}

The five years preceding the death of Martin I the privileged groups of Cataluña, confront at the Parliament gathered in Perpignan, Sant Cugat and Barcelona because of the Princedom Political conception, that avoids progress and shows a ruptury between the nobility and cavalry memberships, which explains the defeat of the Count of Urgel at the succession of the Crown of Aragon. 